\title{
Genetic diversity and differentiation among Korean-Holstein, Hanwoo, and Uganda-Holstein breeds
}

\author{
G. Bigirwa ${ }^{1,2}$, D. $\mathrm{Kim}^{2}$, O. $\mathrm{Acai}^{1}$, C. $\mathrm{Na}^{2}$, J. $\mathrm{Oh}^{2 \#}$ \& K. Song ${ }^{2,3 \#}$ \\ ${ }^{1}$ College of Veterinary Medicine, Animal Resources and Biosecurity, Makerere University, Uganda \\ ${ }^{2}$ Department of Animal Biotechnology, Jeonbuk National University, Jeonju 54896, Korea \\ ${ }^{3}$ Department of Animal Science, Feeds and Animal Nutrition, Faculty of Agriculture, Ankara University, Ankara, \\ 06110, Turkey
}

(Received 2 July 2019; Accepted 22 November 2019; First published online 1 January 2020)

\begin{abstract}
Copyright resides with the authors in terms of the Creative Commons Attribution 4.0 South African License.
See: http://creativecommons.org/licenses/by/4.0/za

Condition of use: The user may copy, distribute, transmit and adapt the work, but must recognize the authors and the South African Journal of Animal Science.
\end{abstract}

\begin{abstract}
The aim of this research was to assess genetic diversity of Korean-Holstein, Korean Hanwoo, and Ugandan-Holstein dairy cattle. DNA was extracted from either blood or hair of Korean-Holstein $(n=74)$, Korean-Hanwoo $(n=75)$ and Ugandan-Holstein $(N=77)$ using AccuPrep ${ }^{\circledR}$ PCR purification kit. The DNA samples were amplified by multiplex polymerase chain reaction, using GeneTrack ${ }^{\mathrm{TM}}$ Hanwoo genotyping kit and assayed using ABI genetic analyser 3130XL. Number of alleles, expected heterozygosity $\left(H_{e}\right)$, observed heterozygosity $\left(\mathrm{H}_{0}\right)$, and the polymorphism information content (PIC) were estimated from 10 microsatellite loci in the three breeds. In addition, $F$-statistics for each of the 10 microsatellites in the three cattle breeds were estimated using fstat version 2.9.3.2 computer program. GENETIX (v.4.02) was used to perform factorial correspondence analysis (FCA) from the allele frequencies and multi-locus clustering was done using STRUCTURE analyses. A total of 124 alleles were detected. The number of alleles per locus varied from eight (TGLA126) to 22 (TGLA122), with an overall mean of 12.2. Expected heterozygosity ranged from 0.617 (SPS115) to 0.854 (TGLA53) and averaged 0.761 . Observed heterozygosity ranged from 0.6 (SPS115) to 0.859 (TGLA53); and averaged 0.761. The mean PIC was 0.723; and means of the F-statistics $\mathrm{F}_{\mathrm{IT}}, \mathrm{F}_{\mathrm{ST}}$ and $\mathrm{F}_{\mathrm{IS}}$ were $0.077,0.076$ and 0.001 respectively. Although FCA revealed clear differentiation of Uganda-Holstein, Korean-Holstein, and Hanwoo, clustering assignments showed genetic admixture between Ugandan dairy cattle (Uganda-Holstein) and Hanwoo. In conclusion, the allelic variation present at the 10 loci was sufficient to categorize these cattle into distinct breed groups.
\end{abstract}

Keywords: dairy cattle, genetic differentiation, F-statistics, heterozygosity, microsatellite

\#Corresponding authors: oh5ow@naver.com, kiduk.song@jbnu.ac.kr

\section{Introduction}

Genetic improvement of dairy cattle is considered indispensable to increasing milk production and fostering animals' adaptability to farming environments in many countries around the world (Olesen et al., 2000; Rischkowsky \& Pilling, 2007). For this reason, several breeding programmes have chosen to employ a few high-producing dairy animals as parent stock, which are multiplied with assisted reproductive technologies (Goddard \& Hayes, 2007; Schefers \& Weigel, 2012). At the same time, the necessity to clearly define breed-specific attributes through genomic studies among cattle populations has been pointed out as a key factor for sustainable dairy genetic improvement programmes (Kim et al., 2017; Tixier-Boichard et al., 2015). Moreover, genomic studies have been used to assess the levels of genetic diversity of cattle breeds, which is necessary for conserving breeds and designing future genetic improvement programmes (Biscarini et al., 2015).

DNA-based tools such as microsatellite analyses have been developed and are now widely used for genetic diversity assessment in dairy breeding programmes (Silva et al., 2014). Additionally, microsatellite markers are used for identification of parental lineages (Erhardt \& Weimann, 2007), mapping genes for economically important traits (Goddard \& Hayes, 2007; Naicy, 2008), and aiding in marker-assisted selection (MAS) (Oltenacu \& Broom, 2010; Schefers \& Weigel, 2012). Microsatellites have been commended for use 
in genetic diversity studies because of their accuracy, versatility, abundancy and being spread over the entire genome (Agung et al., 2019; Erhardt \& Weimann, 2007).

Worldwide, the Holstein-Friesian is regarded as the highest milk producing breed of cattle (Oltenacu \& Broom, 2010; Robinson et al., 2011). In Uganda, dairy cattle constitute only 6-7\% of the national herd, and dairy genetic improvement has been implemented through crossbreeding with imported Holstein semen and embryos from foreign countries (Mugisha et al., 2014). In particular, the major dairy cattle breed in Uganda, which is also referred to as 'Uganda-Holstein', has been produced through crossbreeding Ankole with Holstein cattle. This programme has been implemented over the last 50 years (Galukande, 2010; Kim et al., 2017). However, this approach has not been supported with modern genomic tools to assess the genetic diversity of bred dairy cattle in Uganda and the introduced exotic dairy breeds. As part of the Ugandan dairy genetic improvement programme, the Korean-dairy breeding programme was launched in 2014 to improve dairy cattle production by using germplasm from Korean-Holstein. In this study, the authors used microsatellite markers to assess the genetic diversity of dairy cattle in Uganda in relation to Korean-Holstein and Korean-Hanwoo.

\section{Materials and Methods}

This study was conducted after a review by the Ethical Committee of the School of Veterinary Medicine and Animal Resources, Makerere University (Reference: SVARREC/10/2018), and approved for compliance with animal use standards. Approximately 50 tail-hairs were gathered and pulled firmly from the skin to secure hair-roots.

DNA was extracted from hair samples of Korean-Holstein $(n=74)$, Hanwoo $(n=75)$ and UgandaHolstein ( $n=77$ ) using AccuPrep $₫$ PCR Purification Kit (Bioneer, SK). Ten microsatellites (Table 1), which are recommended by the International Society for Animal Genetics for parentage assessment in cattle were used. Microsatellites were amplified in multiplex PCR reactions using GeneTrack ${ }^{\mathrm{TM}}$ Hanwoo genotype kit (TNT Research, Republic of Korea) according to the manufacturer's instructions. The resultant fluorescent labelled PCR products were separated in the ABI genetic analyser $3500 \mathrm{XL}$, as per the manufacturer's instructions. The number of alleles, observed heterozygosity $\left(H_{0}\right)$ and expected heterozygosity $\left(H_{e}\right)$, and polymorphism information content (PIC) were calculated for each microsatellite marker using the microsatellite tool kit (Park, 2001). Wright's F-statistics ( $F_{I S}, F_{I T}$ and $\left.F_{S T}\right)$ were calculated for each locus across the three breed populations using the fstat version 2.9.3.2 computer program (Goudet, 2002). GENETIX (version 4.02) program was used to perform factorial correspondence analysis (Belkhir et al., 2001). Clustering assignments of the three breeds were obtained by using STRUCTURE version 2.3.4 (Pritchard et al., 2000).

\section{Results}

The number of alleles, $\mathrm{H}_{E}, \mathrm{H}_{\mathrm{O}}$ and PIC for the three cattle breed populations are shown in Table 2. A total of 124 alleles were detected at 10 microsatellite loci across the three breeds. The number of alleles at each locus varied between eight (TGLA126) and 22 (TGLA122), with an overall mean allele number of 12.2. Expected heterozygosity ranged between 0.617 (SPS115) and 0.854 (TGLA53) with an average of 0.761. Observed heterozygosity varied between 0.6 (SPS115) and 0.859 (TGLA53), with a mean of 0.761 . The mean PIC was 0.723.

Microsatellite polymorphism results for individual cattle breed are shown in Table 3. The UgandaHolstein showed the greatest overall $H_{E}(0.799)$ and the Korean-Holstein had the lowest $H_{E}(0.717)$. Observed heterozygosity was greatest in Hanwoo (0.811) and lowest in Korean-Holstein.

The estimates of PIC and F-statistics $\left(F_{I S}, F_{I T}\right.$ and $\left.F_{S T}\right)$ are shown in Table 4. Overall, the mean PIC was higher in Uganda-Holstein than in Korea-Holstein and Hanwoo. Moreover, PIC results from all microsatellite loci were still higher in Uganda-Holstein than in Korea-Holstein and Hanwoo. The total inbreeding estimates per locus $\left(\mathrm{F}_{\mathrm{IT}}\right)$ ranged from 0.003 (ETH10) to 0.214 (ETH225) across the three breed populations, with the overall mean of 0.077 . The lowest and highest within-population inbreeding estimate values $\left(F_{I S}\right)$ were -0.005 (TGLA52) and $0.088(E T H 225)$, respectively. Genetic differentiation ( $\left.F_{S T}\right)$ was observed in all markers, with the highest estimate in ETH3 marker. 
Table 1 Microsatellite primers used to assess genetic diversity in Korean-Holstein, Korean Hanwoo and Uganda-Holstein

\begin{tabular}{|c|c|c|c|}
\hline $\begin{array}{l}\text { Microsatellite } \\
\text { marker }\end{array}$ & $\begin{array}{l}\text { Size range } \\
\text { (bp) }\end{array}$ & Primer sequence $\left(5^{\prime}-3^{\prime}\right)$ & Reference \\
\hline BM2113 & $125-143$ & $\begin{array}{l}\text { Forward: GCT GCC TTC TAC CAA ATA CCC } \\
\text { Reverse: CTT CCT GAG AGA AGC AAC ACC }\end{array}$ & Bishop et al., 1994 \\
\hline ETH10 & $210-226$ & $\begin{array}{l}\text { Forward: GTT CAG GAC TGG CCC TGC TAA CA } \\
\text { Reverse: CCT CCA GCC CAC TTT CTC TTC TC }\end{array}$ & Toldo et al., 1993 \\
\hline ETH225 & $140-156$ & $\begin{array}{l}\text { Forward: GAT CAC CTT GCC ACT ATT TCC T } \\
\text { Reverse: ACA TGA CAG CCA GCT GCT ACT }\end{array}$ & Toldo et al., 1993 \\
\hline ETH3 & $117-129$ & $\begin{array}{l}\text { Forward: GAACCTGCCTCTCCTGCATTGG } \\
\text { Reverse: ACTCTGCCTGTGGCCAAGTAGG }\end{array}$ & Toldo et al., 1993 \\
\hline INRA023 & $197-223$ & $\begin{array}{l}\text { Forward: GAG TAG AGC TAC AAG ATA AAC TTC } \\
\text { Reverse: TAA CTA CAG GGT GTT AGA TGA ACT C }\end{array}$ & Vaiman et al., 1992 \\
\hline SPS115 & $234-252$ & $\begin{array}{l}\text { Forward: AAA GTG ACA CAA CAG CTT CTC CAG } \\
\text { Reverse: AAC GAG TGT CCT AGT TTG GCT GTG }\end{array}$ & Bishop et al., 1994 \\
\hline TGLA122 & $130-193$ & $\begin{array}{l}\text { Forward: CCC TCC TCC AGG TAA ATC AGC } \\
\text { Reverse: AAT CAC ATG GCA AAT AAG TAC ATA }\end{array}$ & Barendse et al., 1992 \\
\hline TGLA126 & $104-133$ & $\begin{array}{l}\text { Forward: CTA ATT TAG AAT GAG AGA GGC TTC T } \\
\text { Reverse: TTG GTC TCT ATT CTC TGA ATA TTC C }\end{array}$ & Barendse et al., 1992 \\
\hline TGLA227 & $64-115$ & $\begin{array}{l}\text { Forward: CGA ATT CCA AAT CTG TTA ATT TGC T } \\
\text { Reverse: ACA GAC AGA AAC TCA ATG AAA GCA }\end{array}$ & Barendse et al., 1992 \\
\hline TGLA53 & $144-178$ & $\begin{array}{l}\text { Forward: GCTTTCAGAAATAGTTTGCATTCA } \\
\text { Reverse: ATCTTCACATGATATTACAGCAGA }\end{array}$ & Barendse et al., 1992 \\
\hline
\end{tabular}

Table 2 Estimates of expected and observed heterozygosity and polymorphism information content for 10 microsatellite loci that were assessed in Korean-Holstein, Hanwoo, Uganda-Holstein

\begin{tabular}{lrccc}
\hline Locus & $\begin{array}{c}\text { No. of } \\
\text { Alleles }\end{array}$ & $\mathrm{H}_{\mathrm{e}}$ & $\mathrm{H}_{\mathrm{o}}$ & $\mathrm{PIC}$ \\
\hline BM2113 & 11 & & & \\
ETH10 & 9 & 0.789 & 0.818 & 0.751 \\
ETH225 & 9 & 0.775 & 0.801 & 0.739 \\
ETH3 & 11 & 0.744 & 0.679 & 0.705 \\
INRA23 & 11 & 0.702 & 0.682 & 0.655 \\
SPS115 & 9 & 0.793 & 0.800 & 0.755 \\
TGLA122 & 22 & 0.617 & 0.600 & 0.578 \\
TGLA126 & 8 & 0.828 & 0.850 & 0.803 \\
TGLA227 & 15 & 0.652 & 0.693 & 0.585 \\
TGLA53 & 17 & 0.853 & 0.822 & 0.829 \\
Overall Mean & 12.2 & 0.854 & 0.859 & 0.832 \\
& & 0.761 & 0.761 & 0.723 \\
\hline
\end{tabular}

$\mathrm{H}_{\mathrm{e}}$ : expected heterozygosity, $\mathrm{H}_{\mathrm{o}}$ : observed heterozygosity, PIC: polymorphism information content 
Table 3 Expected and observed heterozygosity and F-statistics for 10 loci from Korean-Holstein, Hanwoo, Uganda-Holstein

\begin{tabular}{|c|c|c|c|c|c|c|c|c|c|}
\hline \multirow{2}{*}{$\begin{array}{l}\text { Microsatellite } \\
\text { marker }\end{array}$} & \multicolumn{2}{|c|}{ UH } & \multicolumn{2}{|c|}{$\mathrm{KH}$} & \multicolumn{2}{|c|}{ HAN } & \multirow{2}{*}{$\mathrm{F}_{\mathrm{IT}}$} & \multirow{2}{*}{$\mathrm{F}_{\mathrm{ST}}$} & \multirow{2}{*}{$\mathrm{F}_{\mathrm{IS}}$} \\
\hline & $\mathrm{H}_{\mathrm{e}}$ & $\mathrm{H}_{\mathrm{o}}$ & $\mathrm{H}_{\mathrm{e}}$ & $\mathrm{H}_{\mathrm{o}}$ & $\mathrm{H}_{\mathrm{e}}$ & $\mathrm{H}_{\mathrm{o}}$ & & & \\
\hline BM2113 & 0.867 & 0.844 & 0.731 & 0.811 & 0.769 & 0.800 & 0.030 & 0.064 & -0.036 \\
\hline ETH10 & 0.817 & 0.753 & 0.719 & 0.757 & 0.788 & 0.893 & 0.003 & 0.035 & -0.033 \\
\hline ETH225 & 0.850 & 0.688 & 0.746 & 0.671 & 0.637 & 0.680 & 0.214 & 0.138 & 0.088 \\
\hline ETH3 & 0.694 & 0.584 & 0.692 & 0.622 & 0.721 & 0.840 & 0.194 & 0.169 & 0.030 \\
\hline INRA23 & 0.836 & 0.789 & 0.758 & 0.797 & 0.786 & 0.813 & 0.044 & 0.052 & -0.009 \\
\hline SPS115 & 0.605 & 0.595 & 0.547 & 0.500 & 0.698 & 0.707 & 0.063 & 0.038 & 0.026 \\
\hline TGLA122 & 0.816 & 0.779 & 0.826 & 0.838 & 0.843 & 0.933 & 0.060 & 0.084 & -0.026 \\
\hline TGLA126 & 0.751 & 0.805 & 0.529 & 0.568 & 0.676 & 0.707 & 0.018 & 0.076 & -0.063 \\
\hline TGLA227 & 0.889 & 0.857 & 0.808 & 0.743 & 0.862 & 0.867 & 0.089 & 0.055 & 0.036 \\
\hline TGLA53 & 0.872 & 0.818 & 0.816 & 0.892 & 0.874 & 0.867 & 0.034 & 0.038 & -0.005 \\
\hline Overall Mean & 0.799 & 0.751 & 0.717 & 0.719 & 0.765 & 0.811 & 0.077 & 0.076 & 0.001 \\
\hline
\end{tabular}

UH: Uganda-Holstein, KH: Korea-Holstein, HAN: Hanwoo, $\mathrm{H}_{\mathrm{e}}$ : expected heterozygosity, $\mathrm{H}_{\mathrm{o}}$ : observed heterozygosity, $\mathrm{F}_{\mathrm{IT}}$ : total inbreeding estimate, $\mathrm{F}_{\mathrm{ST}}$ : measurement of population differentiation, $\mathrm{F}_{\mathrm{IS}}$ : within-population inbreeding estimate.

Table 4 Polymorphism information content of 10 microsatellite loci in Korean-Holstein, Hanwoo, and Uganda-Holstein

\begin{tabular}{lccc}
\hline \multirow{2}{*}{ Microsatellite Marker } & \multicolumn{3}{c}{ Polymorphism information content } \\
\cline { 2 - 4 } & Uganda-Holstein & Korea-Holstein & Hanwoo \\
\hline BM2113 & 0.847 & 0.678 & 0.727 \\
ETH10 & 0.792 & 0.677 & 0.752 \\
ETH225 & 0.826 & 0.701 & 0.590 \\
ETH3 & 0.667 & 0.630 & 0.667 \\
INRA23 & 0.809 & 0.709 & 0.747 \\
SPS115 & 0.579 & 0.512 & 0.645 \\
TGLA122 & 0.796 & 0.796 & 0.817 \\
TGLA126 & 0.714 & 0.414 & 0.629 \\
TGLA227 & 0.873 & 0.776 & 0.839 \\
TGLA53 & 0.856 & 0.785 & 0.855 \\
Overall mean & 0.776 & 0.668 & 0.727 \\
& & & \\
\hline
\end{tabular}

The factorial correspondence analysis of allele frequencies for the 10 microsatellite loci revealed the very clear separation between the Uganda-Holstein, Korean-Holstein and Hanwoo (Figure 1). The FCA plot shows $62 \%$ of total variance was accounted for by Axis 1 , and $32 \%$ was explained by Axis 2 , which in large part separated Uganda-Holstein from Korean-Holstein and Hanwoo. Multi-locus clustering structure of the three populations is shown in Figure 2 . The breeds were clearly separated into three distinct groups. 


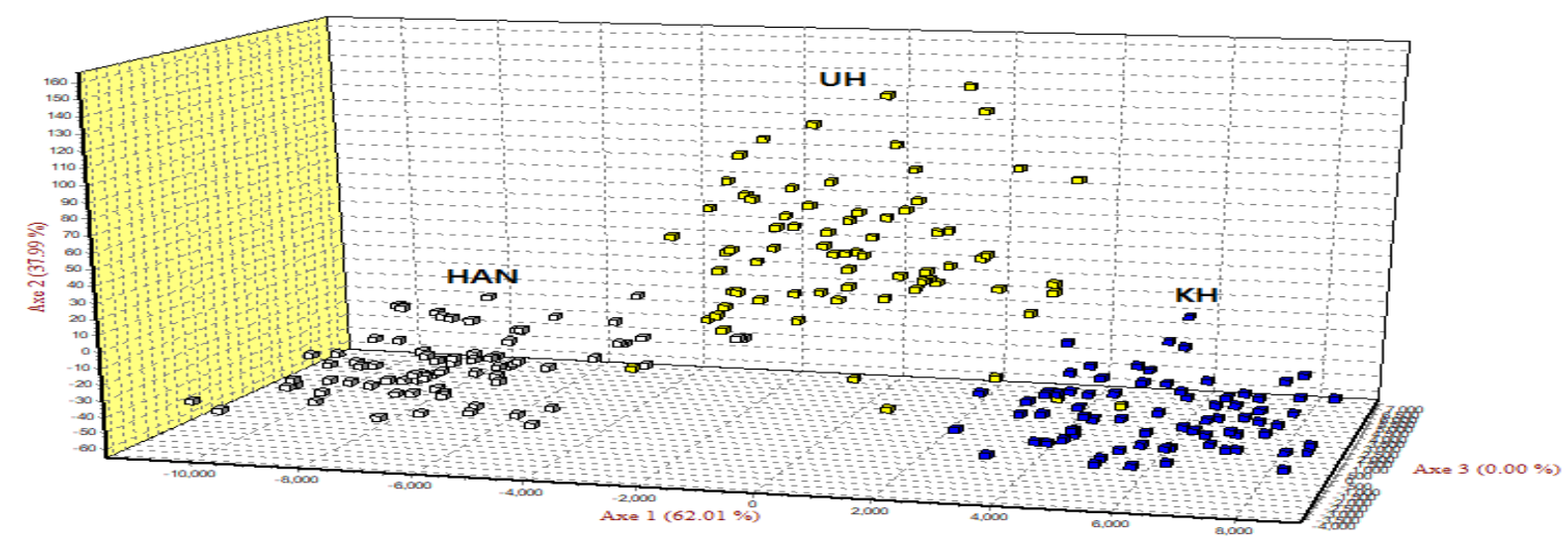

Figure 1 Factorial correspondence analysis of allele frequencies from 10 microsatellite loci in KoreanHolstein, Hanwoo, Uganda-Holstein

HAN: Hanwoo, UH: Uganda-Holstein, KH: Korean-Holstein

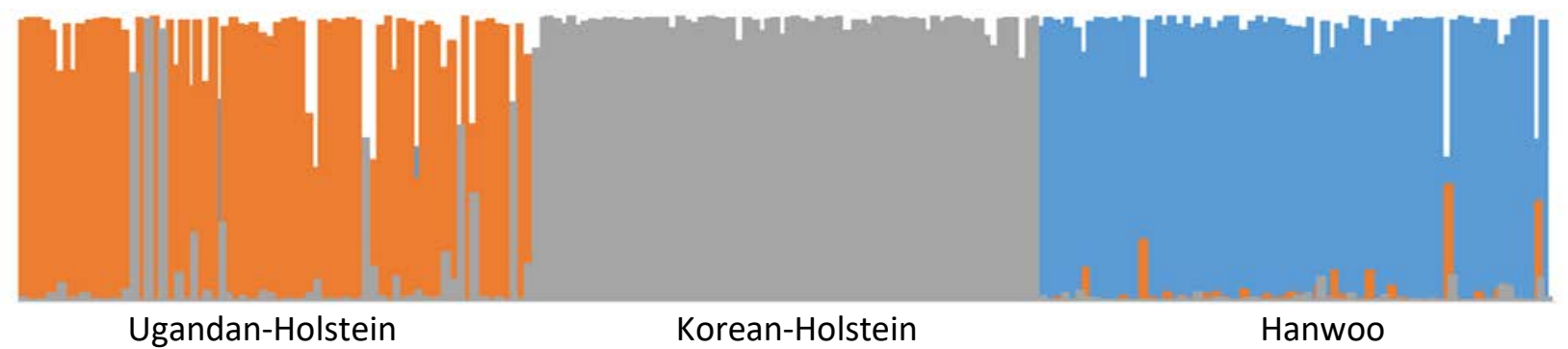

Figure 2 Clustering assignment with $k=3$ of Ugandan Holstein, Korean Holstein and Hanwoo samples

Each of the 226 animals is represented by a thin vertical line that is divided into segments of height proportional to the population represented and colour, which corresponds to the founder population

\section{Discussion}

The number of microsatellite alleles at each locus has been used to assess genetic diversity and between-breed relationships (Egito et al., 2007; Mateus et al., 2004; Suh et al., 2014; Stevanovic et al., 2010). The overall mean allele number per locus was comparable with previous results, which varied from 5 to 16 (Egito et al., 2007; Freeman et al., 2004; Mateus et al., 2004; Stevanovic et al., 2010; Suh et al., 2014, Zhao et al., 2017). Additionally, it has been suggested that individual microsatellite markers that are used to assess genetic diversity should have at least four alleles in order to generate reliable information (Barker, 1994; Shi et al., 2010). Here, the number of alleles per locus satisfies this recommendation. Although 30 loci are recommended for genetic diversity studies in cattle (Erhardt \& Weimann, 2007), the use of 10 microsatellite markers in this study was able to differentiate the three breeds of cattle adequately. Similarly, proven genetic diversity studies among cattle breeds have been undertaken using 10 microsatellites (Zhou et al., 2005; Cervini et al., 2006).

In general, the levels of heterozygosity $\left(\mathrm{H}_{\mathrm{e}}\right.$ and $\left.\mathrm{H}_{0}\right)$ that were observed in this study are similar to previous reports (Agung et al., 2019; Egito et al., 2007; Freeman et al., 2004; Suh et al., 2014; Zhao et al., 2017). Given that these observed levels of heterozygosity were greater than 0.5 , this indicates that the 10 microsatellite markers are suitable for genetic diversity studies in the three dairy breeds (Sheriff \& Alemayehu, 2017).

The estimates of $\mathrm{H}_{e}$ and $\mathrm{H}_{\mathrm{o}}$ in Hanwoo and Korean-Holstein that were observed in this study were similar to or slightly greater than those reported previously for the two breeds (Hanwoo: $\mathrm{H}_{\mathrm{e}}=0.713$ to 0.740 and $\mathrm{H}_{\mathrm{o}}=0.68$ to 0.7442 ; and Korean-Holstein: $\mathrm{H}_{\mathrm{e}}=0.701$ to 0.7361 and $\mathrm{H}_{\mathrm{o}}=0.715$ to 0.753 ) (Kim et al., 2002, Shi et al., 2010, Suh et al., 2014). Any perceived discrepancy in $\mathrm{H}_{\mathrm{e}}$ and $\mathrm{H}_{\mathrm{o}}$ among studies could be as a result of differences in the numbers of animals and in the laboratory settings, which could lead to 
genotyping errors (Egito et al., 2007; Suh et al., 2014). The Korean Holstein group that was characterized in this study was found to be less heterozygous than the Hanwoo cattle, in agreement with Choi et al. (2012). Compared with the Hanwoo and Korean-Holstein, the value of $\mathrm{H}_{\mathrm{e}}$ in Uganda-Holstein was greater than $\mathrm{H}_{0}$ for nine of the microsatellites (Table 3). This observed greater $\mathrm{H}_{e}$ compared with $\mathrm{H}_{o}$ in Uganda-Holstein could be attributed to haphazard and unregulated breeding practices among Uganda dairy cattle herds (Mugisha et al., 2014). In the present study, a low estimate of genetic differentiation $\left(F_{S T}=0.076\right)$ between the studied breeds was identified, indicating that the three cattle breed populations could have close proximity and share the same ancestry. These populations are all taurine breeds and could have common alleles in their genomes. An inbreeding coefficient $\left(F_{I S}\right)$ of $1 \%$ identified in this study could be an indication of limited inbreeding within the three populations. Moreover, there was a significant shortfall in the total inbreeding estimates (mean $\left.\mathrm{F}_{\mathrm{IT}}=0.077\right)$ across the three populations. However, the indices of $F$-statistics $\left(\mathrm{F}_{\mathrm{IS}}, \mathrm{F}_{\mathrm{ST}}\right.$ and $\mathrm{F}_{\mathrm{IT}}$ ) that were obtained in the current study population were equivalent to those reported among taurine breeds (Suh et al., 2014; Mateus et al., 2004). The PIC values for the 10 markers in this study ranged between 0.578 (SPS115) and 0.832 (TGLA53) (Table 4), suggesting that the microsatellite markers used in this study were informative.

The clear separation between the Uganda-Holstein, Korean-Holstein and Hanwoo that is revealed in the FCA (Figure 1) suggests that these breeds are distinct. A previous study on the genetic structure of Korean native breeds revealed similar findings for Hanwoo and Korean-Holstein (Suh et al., 2014). In this study, the Ugandan-Holstein was clearly separated from Hanwoo and Korean-Holstein. The differences in the level of alleles that are present in animals have been shown to contribute to distinction between breeds (Egito et al., 2007; Mateus et al., 2004). The results from the current study therefore suggest that each of the breeds has distinct genetic characteristics, which can be utilized when designing conservation and breeding programmes. A previous study using single nucleotide polymorphisms (SNPs) revealed genetic heterogeneity and shared ancestry between Ankole cattle and other taurine breeds, including Hanwoo (Kim et al., 2017). Most dairy cattle in Uganda are products of crossbreeding Holstein with Ankole cattle (Galukande, 2010; Kim et al., 2017).

\section{Conclusion}

From the present study, all 10 markers displayed a significant abundance of heterozygosity and were effective in determining the genetic diversity of the three breeds. The alleles identified in this study were able to separate the breeds into three distinct clusters, that is, Korean-Holstein, Uganda-Holstein and Hanwoo. Further comparative studies on historical, cultural, animal phenotype and environmental aspects regarding breeding programmes in these breeds are recommended.

\section{Acknowledgements}

This work was supported by grants from the Korea Institute of Planning and Evaluation for Technology in Food, Agriculture, Forestry (IPET) funded by Ministry of Agriculture, Food and Rural Affairs (MAFRA, 316084 - 03), Republic of Korea, and the Next-Generation BioGreen 21 Program (No. PJ01315101), Rural Development Administration, Republic of Korea.

\section{Authors' Contributions}

KDS, JOA and JDO designed the study, GB collected the blood samples and isolated the DNA. GB, DHK, JDO and CSN performed the molecular genetic and statistical analyses. All authors contributed to manuscript writing.

\section{Conflict of Interest Declaration}

The authors declare that they have no conflict of interest.

\section{References}

Agung, P.P., Saputra, F., Zein, M.S.A., Wulandari, A.S., Putra, W.P.B., Said, S. \& Jakaria, J., 2019. Genetic diversity of Indonesian cattle breeds based on microsatellite markers. Asian-Austral. J. Anim. Sci. 32, 467-476.

Barendse, W., Armitage, S.M., Kossarek, L.M., Shalom, A., Kirkpatrick, B.W., Ryan, A.M., Clayton, D., Li, L., Neibergs, H.L., Zhang, N., Grosse, W.M., Weiss, J., Creighton, P., McCarthy, F. Ron, M., Teale, A.J., Fries, R., McGraw, R.A., Moore, S.S., Georges, M., Soller, M., Womack, J.E. \& Hetzel, D.J.S., 1994. A genetic linkage map of the bovine genome. Nat. Genet. 6:227.

Barker, J., 1994. A global protocol for determining genetic distances among domestic livestock breeds. In: Proceedings of the 5th World Congress on Genetics Applied to Livestock Production. Guelph and Ontario, Canada. 21, 501508.

Belkhir, K., Borsa, P., Chikhi, L., Raufaste, N. \& Bonhomme, F., 2001. GENETIX 4.02, logiciel sous Windows TM pour la génétique des populations, Laboratoire Génome, Populations, Interactions. CNRSUMR. 5,000, Université de Montpellier II, Montpellier, France.

Biscarini, F., Nicolazzi, E.L., Stella, A., Boettcher, P.J. \& Gandini, G., 2015. Challenges and opportunities in genetic improvement of local livestock breeds. Front. Genet. 6, 33. 
Bishop, M.D., Kappes, S.M., Keele, J.W., Stone, R.T., Sunden, S.L., Hawkins, G.A., Toldo, S.S., Fries, R., Grosz, M.D. and Yoo, J., 1994. A genetic linkage map for cattle. Genetics 136(2), 619-639.

Cervini, M., Henrique-Silva, F., Mortari, N. \& Matheucci Jr, E. 2006. Genetic variability of 10 microsatellite markers in the characterization of Brazilian Nellore cattle (Bos indicus). Genet. Mol. Biol. 29(3), 486-490.

Choi, T., Lee, S., Yoon, D., Kang, H., Kim, C., Hwang, I., Kim, C., Jin, X., Yang, C. \& Seo, K., 2012. Determination of genetic diversity among Korean Hanwoo cattle based on physical characteristics. Asian-Austral. J. Anim. Sci. 25, 1205.

Egito, A.A., Paiva, S.R., Maria Do Socorro, M., Mariante, A.S., Almeida, L.D., Castro, S.R. \& Grattapaglia, D., 2007. Microsatellite based genetic diversity and relationships among ten Creole and commercial cattle breeds raised in Brazil. BMC Genet. 8, 83.

Erhardt, G. \& Weimann, C., 2007. Use of molecular markers for evaluation of genetic diversity and in animal production. Arch. Latinoam. Prod. Anim.15 (1), 63-66.

Freeman, A., Meghen, C., Machugh, D., Loftus, R., Achukwi, M., Bado, A., Sauveroche, B. \& Bradley, D., 2004. Admixture and diversity in West African cattle populations. Mol. Eco. 13, 3477-3487.

Galukande, G.E., 2010. Comparison of production systems with purebred Ankole vs. crossbred Ankole-Friesian animals on-farm using a combined cross-sectional and longitudinal approach (Kiruhura District of Uganda). PhD thesis, University of Natural Resources and Applied Life Sciences, Vienna, Austria.

Goddard, M. \& Hayes, B., 2007. Genomic selection. J. Anim. Breed. Genet. 124, 323-330.

Goudet, J. 2002. FSTAT computer package for PCs. Institute of Ecology, UNIL, Lausanne, Switzerland.

Kim, J., Hanotte, O., Mwai, O.A., Dessie, T., Bashir, S., Diallo, B., Agaba, M., Kim, K., Kwak, W., Sung, S., Seo, M., Jeong, H., Kwon, T., Taye, M., Song, K., Lim, D., Cho, S., Lee, H., Yoon, D., Oh, S.J., Kemp, S., Lee H., \& Kim, H., 2017. The genome landscape of indigenous African cattle. Genome Bio. 18, 34.

Mateus, J., Penedo, M., Alves, V., Ramos, M. \& Rangel-Figueiredo, T., 2004. Genetic diversity and differentiation in Portuguese cattle breeds using microsatellites. Anim. Genet. 35, 106-113.

Mugisha, A., Kayiizi, V., Owiny, D. \& Mburu, J., 2014. Breeding services and the factors influencing their use on smallholder dairy farms in Central Uganda. Vet. Med. Int. 169380, 1-6.

Naicy, T., 2008. Genetic characteristics of five microsatellite markers associated with milk production traits in crossbred dairy cattle of Kerala. Vet. World. 1, 245.

Olesen, I., Groen, A.F. \& Gjerde, B., 2000. Definition of animal breeding goals for sustainable production systems. J. Anim. Sci. 78, 570-582.

Oltenacu, P.A. \& Broom, D.M., 2010. The impact of genetic selection for increased milk yield on the welfare of dairy cows. Anim. Welfare. 19, 39-49.

Park, S.D.E., 2001. The Excel microsatellite toolkit (version 3.1) Animal Genomics Laboratory, University College, Dublin, Ireland.

Pritchard, J.K., Stephens, M., Rosenberg, N.A. \& Donnelly, P., 2000. Association mapping in structured populations. Am. J. Hum. Genet., 67:170-181.

Rischkowsky, B. \& Pilling, D., 2007. The state of the world's animal genetic resources for food and agriculture, Food \& Agriculture Org.

Robinson, T.P., Thornton P.K., Franceschini, G., Kruska, R.L., Chiozza, F., Notenbaert, A., Cecchi, G., Herrero, M., Epprecht, M., Fritz, S., You, L., Conchedda, G. \& See, L., 2011. Global livestock production systems. Food and Agriculture Organization of the United Nations and International Livestock Research Institute, Rome, Italy.

Schefers, J.M. \& Weigel, K.A., 2012. Genomic selection in dairy cattle: Integration of DNA testing into breeding programs. Anim. Front. 2, 4-9.

Sheriff, O. \& Alemayehu, K., 2017. Genetic diversity studies using microsatellite markers and their contribution in supporting sustainable sheep breeding programs. Asian J. Agric. 1, 46-51.

Shi, Z., Lee, J.-H., Lee, Y.-S., Oh, D.-Y. \& Yeo, J.-S., 2010. Analysis of genetic diversity and distances in Asian cattle breeds using microsatellite markers. J. Korean Data. Inform. Sci. Soc. 21, 795-802.

Silva, M.V., Dos Santos, D.J., Boison, S.A., Utsunomiya, A.T., Carmo, A.S., Sonstegard, T.S., Cole, J.B. \& Van Tassell, C.P., 2014. The development of genomics applied to dairy breeding. Livest. Sci. 166, 66-75.

Stevanovic, J., Stanimirovic, Z., Dimitrijevic, V. \& Maletic, M., 2010. Evaluation of 11 microsatellite loci for their use in paternity testing in Yugoslav Pied cattle (YU Simmental cattle). Czech J. Anim. Sci. 55, 221-226.

Suh, S., Kim, Y.-S., Cho, C.-Y., Byun, M.-J., Choi, S.-B., Ko, Y.-G., Lee, C. W., Jung, K.-S., Bae, K. H. \& Kim, J.-H., 2014. Assessment of genetic diversity, relationships and structure among Korean native cattle breeds using microsatellite markers. Asian-Austral. J. Anim. Sci. 27, 1548.

Tixier-Boichard, M., Verrier, E., Rognon, X. \& Zerjal, T., 2015. Farm animal genetic and genomic resources from an agroecological perspective. Front. Genet. 6, 153.

Toldo, S.S., Fries, R., Steffen, P., Neiberg, H.L., Barendse, W., Womack, J.E., Hetzel, D.J.S. \& Stranzinger, G., 1993. Physically mapped, cosmid-derived microsatellite markers as anchor loci on bovine chromosomes. Mamm. Genome. 4(12), 720-727.

Vaiman, D., Mercier, D., Moazami-Goudarzi, K., Eggen, A., Ciampolini, R., Lépingle, A., Velmala, R., Kaukinen, J., Varvio, S.L., Martin, P., Levéziel, H. \& Guérin, G., 1994. A set of 99 cattle microsatellites: characterization, synteny mapping, and polymorphism. Mamm. Genome 5(5), 288-297.

Zhao, J., Zhu, C., Xu, Z., Jiang, X., Yang, S. \& Chen, A., 2017. Microsatellite markers for animal identification and meat traceability of six beef cattle breeds in the Chinese market. Food Control 78, 469-475.

Zhou, G.L., Jin, H.G., Zhu, Q., Guo, S.L. \& Wu, Y.H., 2005. Genetic diversity analysis of five cattle breeds native to China using microsatellites. J. Genet. 84(1), 77-80. 